\title{
Desempenho e características de carcaça de suínos em crescimento alimentados com torta de algodão e complexo enzimático
}

\author{
[Performance and carcass characteristics of growing pigs fed diets containing cottonseed \\ cake with and enzyme complex]
D.N.M. Ferreira ${ }^{1}$, W.M. Dutra Júnior ${ }^{2}$, L.O. Palhares ${ }^{1}$, A.H.S.C. Coelho ${ }^{1}$, M.I. Lourenço-Silva ${ }^{2}$, R.L.C. Melo ${ }^{1}$ \\ ${ }^{1}$ Programa de pós-graduação - Universidade Federal Rural de Pernambuco - Recife, PE \\ ${ }^{2}$ Universidade Federal Rural de Pernambuco - Recife, PE
}

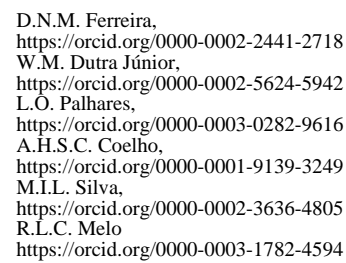

RESUMO

Objetivou-se avaliar o efeito da inclusão da torta de algodão (TA) com adição de enzimas na ração de suínos na fase de crescimento e seus efeitos sobre o desempenho, as características de carcaças, bem como sua viabilidade econômica. Para tanto, foram utilizados 20 suínos machos castrados, distribuídos em um delineamento em blocos ao acaso, com peso corporal inicial de $56,28 \pm 5,78 \mathrm{~kg}$ e final de $79,79 \pm 7,32 \mathrm{~kg}$. Os níveis de inclusão da TA foram $0 \%, 8 \%, 16 \%$ e $24 \%$. Todas as rações tiveram os valores de exigência em energia metabolizável, proteína bruta e fósforo subestimados em 1,5\% com a utilização de 300g/t do complexo enzimático. Os parâmetros de desempenho e as características de carcaça não apresentaram diferenças significativas entre os níveis de inclusão da TA. A torta de algodão pode ser utilizada em até o nível de $24 \%$ de inclusão com adição de complexo enzimático em rações de suínos na fase de crescimento II, sem alterar os parâmetros de desempenho e as características de carcaças, além de apresentar redução do custo/kg de suíno produzido.

Palavras-chave: aditivo, desempenho, Gossypium hirsutum, coprodutos, suinocultura

\begin{abstract}
The objective of this study was to evaluate the inclusion of cottonseed cake $(C C)$ with enzyme complex in the diet of pigs in the growth phase and its effects on performance, carcass characteristics and economic viability. Thus, 20 barrows were distributed in a completely randomized block design, with initial body weight of $56.28 \pm 5.78 \mathrm{~kg}$ and final weight of $79.79 \pm 7.32 \mathrm{~kg}$. The inclusion levels of CC were 0\%, 8\%, 16\% and $24 \%$. All diets had the requirement values of metabolizable energy, crude protein and phosphorus underestimated by $1.5 \%$ and were added to $300 \mathrm{~g} / \mathrm{t}$ enzyme complex. The performance parameters and carcass characteristics there was no difference between the levels of inclusion of cottonseed cake. The cottonseed cake can be used up to the $24 \%$ inclusion level with addition of enzyme complex in the growth phase II, without affecting performance and carcass characteristics, besides reducing the cost/kg of pig produced.
\end{abstract}

Keywords: additive, performance, gossypium hirsutum, co-products, swine production

\section{INTRODUÇÃO}

A suinocultura brasileira tem melhorado os índices de produtividade ao longo dos últimos anos. Atualmente, o Brasil é o quarto maior produtor mundial de carne suína, após a China, a União Europeia e os Estados Unidos
(Relatório..., 2016). Para acompanhar a produtividade em escala internacional, tem-se investido na ampliação do plantel para aumento da produção e na modernização do sistema. Consequentemente, com o aumento do rebanho, houve a necessidade de maior demanda de insumos para elaboração das rações.

Recebido em 2 de janeiro de 2018

Aceito em 9 de novembro de 2018

E-mail: delnathy89@gmail.com 
A alimentação dos suínos é baseada em ingredientes tradicionais, como o milho e o farelo de soja, que tornam essa produção mais onerosa devido aos gastos com frete no transporte e oscilações sazonais de preço dessas matérias-primas no mercado. Por outro lado, a utilização desses alimentos nas rações para animais também compete com a alimentação dos seres humanos, aumentando, assim, o valor final do ingrediente. Uma alternativa para reduzir os custos da ração é a utilização de outros alimentos disponíveis no mercado para alimentação animal.

A torta de algodão (TA) é um coproduto proveniente da extração de óleo da semente do algodão, que possui alto teor de energia e proteína bruta, com menor concentração de lisina quando comparada ao farelo de soja, porém os demais aminoácidos essenciais estão presentes em quantidades aceitáveis.

Como fator limitante na utilização desse coproduto na alimentação de suínos, existe o gossipol, composto que interfere no aproveitamento dos minerais, formando complexos estáveis com cátions de ferro, podendo, assim, ocasionar anemia. Uma solução para isso é a adição de sais de ferro à dieta, como sulfato ferroso, utilizado na proporção 1:1 (ferro:gossipol livre) (Moreira et al., 2006).

Outro componente limitante para o uso da TA são as fibras dietéticas ou polissacarídeos não amiláceos (PNA). Apesar de os PNA serem fermentados no intestino grosso e produzirem os ácidos graxos voláteis (AGV), que são aproveitados de 5 a $28 \%$ da exigência de mantença dos suínos (Grieshop et al., 2001), eles reduzem o desempenho dos animais e aumentam a conversão alimentar, além de poder ser observada diminuição da digestibilidade de energia, proteína, fibra em detergente neutro e fibra em detergente ácido pelos suínos (Urriola e Stein, 2010), o que constitui um fator antinutricional para os animais não ruminantes (Gomes et al., 2007).

No entanto, em pesquisa realizada por Melo et al. (2012), observou-se que a inclusão de até $20 \%$ de farelo de algodão nas rações não afetou o desempenho dos animais. Paiano et al. (2014) também não observaram efeitos significativos sobre as características de carcaça dos suínos até o nível de $15 \%$ de inclusão do farelo de algodão.
Devido à existência de fatores antinutricionais que podem ocasionar interferências na digestibilidade dos alimentos e, consequentemente, no desempenho e na qualidade de carcaça, pesquisas foram realizadas com diferentes alimentos, a fim de avaliar a utilização de enzimas exógenas como aditivos às rações, para promover um melhor aproveitamento desses ingredientes e, assim, favorecer um aumento no rendimento de carcaça dos animais (Fang et al., 2007; Ruiz et al., 2008; Silva et al., 2013).

Diante do exposto, este trabalho foi desenvolvido com o objetivo de avaliar o efeito da inclusão da torta de algodão com adição de enzimas na ração de suínos na fase de crescimento e seu efeito sobre o desempenho e a característica de carcaça, bem como sua viabilidade econômica.

\section{MATERIAL E MÉTODO}

Todos os procedimentos experimentais desenvolvidos foram submetidos à Comissão de Ética no Uso de Animal da UFRPE (CeuaUFRPE), sendo aprovado por meio da licença $\mathrm{n}^{\circ}$ 069/2013.

O experimento foi realizado no setor de suinocultura do Departamento de Zootecnia da Universidade Federal Rural de Pernambuco (UFRPE). Foram utilizados 20 suínos machos castrados, de linhagem comercial (Large White $\mathrm{x}$ Duroc $x$ Landrace), com peso inicial de $56,28 \pm 5,78 \mathrm{~kg}$, alojados em baias individuais com dimensões de 1,20 x $3,10 \mathrm{~m}^{2}$, com comedouro tipo cocho de alumínio e bebedouro tipo chupeta. Cada animal foi considerado uma unidade experimental, e eles foram distribuídos em delineamento experimental de blocos ao acaso, com quatro tratamentos com cinco repetições. Os blocos foram organizados de acordo com o peso corporal inicial dos animais.

Os tratamentos corresponderam às rações com níveis crescentes de inclusão da TA $(0,8,16$ e 24\%) (Tab. 1). Todas as rações contendo enzimas tiveram os valores de energia metabolizável, proteína bruta (PB) e fósforo disponível reduzidos em $1,5 \%$ da exigência para machos castrados de desempenho médio segundo Rostagno et al. (2011). 
Tabela 1. Composição centesimal e calculada (matéria natural) das rações experimentais para suínos na fase de crescimento

\begin{tabular}{|c|c|c|c|c|}
\hline \multirow{2}{*}{ Ingredientes } & \multicolumn{4}{|c|}{ Níveis de torta de algodão (\%) } \\
\hline & 0,0 & 8,0 & 16,0 & 24,0 \\
\hline Milho grão & 76,611 & 71,647 & 65,186 & 58,721 \\
\hline Farelo de soja & 19,707 & 16,512 & 13,562 & 10,617 \\
\hline Torta de algodão & 0,000 & 8,000 & 16,000 & 24,000 \\
\hline Fosfato bicálcico & 0,796 & 0,851 & 0,909 & 0,967 \\
\hline Complexo enzimático & 0,030 & 0,030 & 0,030 & 0,030 \\
\hline Inerte $^{1}$ & 1,233 & 0,500 & 0,500 & 0,500 \\
\hline Calcário & 0,595 & 0,533 & 0,467 & 0,401 \\
\hline Óleo de soja & 0,000 & 0,829 & 2,165 & 3,503 \\
\hline Suplemento vit. e min. ${ }^{2}$ & 0,400 & 0,400 & 0,400 & 0,400 \\
\hline Sal comum & 0,337 & 0,347 & 0,357 & 0,367 \\
\hline DL-metionina & 0,010 & 0,014 & 0,030 & 0,043 \\
\hline L-lisina $\mathrm{HCl}$ & 0,240 & 0,283 & 0,322 & 0,361 \\
\hline L-triptofano & 0,000 & 0,001 & 0,005 & 0,008 \\
\hline L-treonina & 0,041 & 0,055 & 0,069 & 0,083 \\
\hline Total & 100,0 & 100,0 & 100,0 & 100,0 \\
\hline \multicolumn{5}{|c|}{ Composição calculada } \\
\hline Energia met. (kcal/kg) & 3181,0 & 3181,0 & 3181,0 & 3181,0 \\
\hline Proteína bruta $(\%)$ & 15,19 & 15,19 & 15,19 & 15,19 \\
\hline Fibra bruta $(\%)$ & 2,660 & 4,158 & 5,642 & 7,126 \\
\hline Lisina dig. (\%) & 0,823 & 0,823 & 0,823 & 0,823 \\
\hline Metionina dig. (\%) & 0,247 & 0,247 & 0,256 & 0,263 \\
\hline Treonina dig. (\%) & 0,535 & 0,535 & 0,535 & 0,535 \\
\hline Triptofano dig. (\%) & 0,151 & 0,148 & 0,148 & 0,148 \\
\hline Fósforo disp. (\%) & 0,246 & 0,246 & 0,246 & 0,246 \\
\hline Cálcio (\%) & 0,512 & 0,512 & 0,512 & 0,512 \\
\hline Sódio (\%) & 0,170 & 0,170 & 0,170 & 0,170 \\
\hline \multicolumn{5}{|c|}{ Valores analisados } \\
\hline Matéria seca (\%) & 87,72 & 88,39 & 88,51 & 89,26 \\
\hline Energia bruta $(\mathrm{kcal} / \mathrm{kg})$ & 4010 & 4082 & 4072 & 4015 \\
\hline Proteína bruta (\%) & 15,97 & 15,55 & 15,31 & 15,41 \\
\hline Fibra bruta $(\%)$ & 2,07 & 2,92 & 4,99 & 6,09 \\
\hline
\end{tabular}

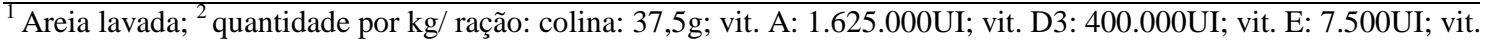
K3: 750mg; vit. B1: 550mg; vit. B2: $1.375 \mathrm{mg}$; vit. B6: 500mg; vit. B12: 5.000mg; niacina: 5.000mg; ácido pantotênico: 2.300mg; ácido fólico: $125 \mathrm{mg}$; biotina: 7,5mg; sulfato de ferro: $25 \mathrm{~g}$; sulfato de cobre: $3.750 \mathrm{mg}$; sulfato de manganês: $12,5 \mathrm{~g}$; sulfato de zinco: $31,25 \mathrm{~g}$; iodato de cálcio: $250 \mathrm{mg}$; selenito de sódio: $75 \mathrm{mg}$.

Previamente, foi realizada análise para determinação da quantidade de gossipol livre (GL), determinada no laboratório Labtron ${ }^{\circledR}$, Itapira/SP. O valor determinado foi de 977ppm de GL. No momento da preparação das rações experimentais, a TA foi tratada com sulfato ferroso na proporção de 1:1 de gossipol livre.

Foi incorporada na ração a quantidade de $300 \mathrm{mg} / \mathrm{kg}$ do complexo enzimático da Bioenzima ${ }^{\circledR}$ contendo: celulase $\left(15,53 \mathrm{U} \mathrm{g}^{-1}\right)$, endoglucanase $\left(27,35 \mathrm{U} \mathrm{g}^{-1}\right)$, xilanase $\left(77,47 \mathrm{U} \mathrm{g}^{-}\right.$ $\left.{ }^{1}\right)$, pectinase $\left(1,259 \times 103 \mathrm{U} \mathrm{g}^{-1}\right), \quad \beta$-glucanase $\left(5,166 \times 102 \mathrm{U} \mathrm{g}^{-1}\right)$, protease $\left(2,955 \times 102 \mathrm{U} \mathrm{g}^{-1}\right)$ e fitase $\left(2,06 \mathrm{U} \mathrm{g}^{-1}\right)$, em que uma unidade de atividade enzimática libera um $\mu \mathrm{mol}$ de nutriente por $\mathrm{g}$ por minuto $\left(\mathrm{U}=\mu \mathrm{mol} \mathrm{g}^{-1}\right)$, segundo recomendações do fabricante.

Os animais receberam água e ração à vontade durante todo o período experimental, sendo as sobras computadas diariamente para quantificação do consumo diário de ração (CDR). Os animais foram pesados a cada 14 dias para avaliação do ganho de peso diário (GDP) e posterior cálculo da conversão alimentar (CA).

Foram coletadas amostras de sangue ao final do período experimental, por meio de punção do sinus orbital dos animais, utilizando-se agulhas hipodérmicas (40 x 1,6mm). Em seguida, as amostras foram acondicionadas em tubos de 
$10 \mathrm{~mL}$ sem anticoagulante, para obtenção do soro, e em tubos de $5 \mathrm{~mL}$ contendo fluoreto de sódio com o ácido etilenodiaminotetracético (EDTA), para obtenção do plasma. Os tubos, com amostras do sangue coletado, foram centrifugados a $3.000 \mathrm{rpm}$, por um período de 10 minutos, para obtenção do plasma e do soro sanguíneo; $2 \mathrm{~mL}$ do sobrenadante foram transferidos para Eppendorfs identificados. As amostras foram submetidas a análises de glicose, proteínas totais, ureia, creatinina, ácido úrico e fósforo em analisador bioquímico semiautomático (Doles D250 ${ }^{\circledR}$ ), utilizando-se os respectivos kits comerciais Doles ${ }^{\circledR}$.

Ao final do experimento, foram selecionados três animais de acordo com o peso médio do tratamento e, após jejum sólido de $18 \mathrm{~h}$, foi realizado o abate no abatedouro municipal de Paulista - PE. A avaliação do comprimento e do rendimento de carcaça, da espessura média de toucinho (ET) e da área de olho de lombo (AOL) foi realizada pelo Método Brasileiro de Avaliação de Carcaças (Métodos, 1973).

A viabilidade econômica das rações foi realizada pela estimativa do custo médio da alimentação por quilograma de suíno produzido e pelo índice de eficiência econômica (IEE) segundo Barbosa et al. (1992).
Os dados obtidos pela experimentação foram submetidos à análise de variância pelo programa estatístico Statistical Analysis System (System..., 2004). Posteriormente, quando necessário, os resultados foram comparados pelo teste de médias de Dunnett ou submetidos à análise estatística de regressão em função dos níveis da torta de algodão nas rações, adotando-se modelos lineares e quadráticos, todos tomando o nível de confiança de $95 \%$.

$\mathrm{O}$ modelo matemático está descrito a seguir: $\mathrm{Y}_{\mathrm{ji}}$ $=\mu+b_{j}+t i+e_{j i}$, em que: $Y_{j i}=$ valor observado $Y$ na unidade experimental que recebeu $o$ tratamento i na repetição $j ; \mu=$ constante; $b_{j}=$ efeito do bloco; $t_{i}=$ efeito do tratamento; eij= erro experimental.

\section{RESULTADOS E DISCUSSÃO}

Os níveis crescentes de inclusão da torta de algodão não alteraram $(\mathrm{P}>0,05)$ os valores dos parâmetros de desempenho dos animais (Tab. 2). A ausência de efeito significativo entre os tratamentos para o consumo diário de ração deveu-se possivelmente ao uso de rações isoenergéticas e isoproteicas; o mesmo resultado foi encontrado por Adeniji e Azeez (2008).

Tabela 2. Variáveis de desempenho de suínos alimentados com rações contendo níveis crescentes de inclusão da torta de algodão na fase de crescimento

\begin{tabular}{lcccccc}
\multicolumn{1}{c}{ Variáveis } & \multicolumn{7}{c}{ Níveis de torta de algodão, \% } & 8,0 & 16,0 & 24,0 & $\mathrm{P}$ & $\mathrm{CV} \%$ \\
\hline Peso final, kg diário de ração $(\mathrm{kg})$ & 79,71 & 82,57 & 81,47 & 76,85 & 0,649 & 9,29 \\
Consumo diă & 3,19 & 3,40 & 3,21 & 3,01 & 0,491 & 9,25 \\
Ganho de peso diário (kg) & 1,09 & 1,20 & 1,13 & 1,10 & 0,344 & 8,87 \\
Conversão alimentar & 2,94 & 2,83 & 2,84 & 2,72 & 0,291 & 5,82 \\
\hline
\end{tabular}

$\mathrm{P}=$ probabilidade; $\mathrm{CV}=$ coeficiente de variação.

Apesar da redução nos valores de energia e proteína bruta em $1,5 \%$ das exigências dos animais, os dados de ganho de peso se mostram superiores aos encontrados na literatura (Adeniji e Azeez, 2008; Meffeja et al., 2007; Mello et al., 2012) quando usados alimentos fibrosos, farelo de algodão (FA) ou TA sem adição de enzimas.

Mesmo com o aumento de 62,67\% de fibra bruta, em relação à ração referência sem TA, não foi observada diferença entre os tratamentos para a conversão alimentar. Geralmente, o consumo tende a diminuir com o aumento da quantidade de fibra na dieta. Isso ocorre devido à sensação de saciedade por preenchimento do trato gastrointestinal causado pelos PNA. O fato de a conversão alimentar não ter sido afetada de acordo com os níveis crescentes de inclusão da TA pode indicar que o alimento testado foi bem aproveitado provavelmente devido à inclusão do complexo enzimático.

As vantagens provenientes do complexo enzimático em dietas para suínos com ingredientes não convencionais são bastante mencionadas na literatura em relação às 
melhorias na digestibilidade e ao aproveitamento dos nutrientes, além da redução da viscosidade das dietas com teores mais elevados de fibra. Hauschild et al. (2008) avaliaram o efeito da inclusão de triticale sobre a digestibilidade de dietas para suínos com ou sem enzimas e encontraram maior disponibilidade de proteína na dieta com a adição de enzimas. LorenaRezende et al. (2012), ao avaliarem a digestibilidade do farelo de algodão com ou sem protease e fitase, observaram melhora na digestibilidade da proteína bruta e menor eliminação do nitrogênio nas fezes pelos animais do tratamento com enzima. Os parâmetros sanguíneos séricos e plasmáticos não foram influenciados $(\mathrm{P}>0,05)$ (Tab. 3), exceto para o ácido úrico (Fig. 1).

Tabela 3. Parâmetros sanguíneos de suínos alimentados com rações contendo níveis crescentes de inclusão da torta de algodão na fase de crescimento

\begin{tabular}{|c|c|c|c|c|c|c|}
\hline \multirow{2}{*}{ Variáveis } & \multicolumn{4}{|c|}{ Níveis de torta de algodão, $\%$} & \multirow[b]{2}{*}{$\mathrm{P}$} & \multirow[b]{2}{*}{ CV \% } \\
\hline & 0,0 & 8,0 & 16,0 & 24,0 & & \\
\hline Proteína total, g/dL & 6,16 & 5,90 & 5,92 & 5,76 & 0,2217 & 4,897 \\
\hline Creatinina, mg/dL & 1,17 & 1,26 & 1,17 & 1,24 & 0,3886 & 8,623 \\
\hline Ureia, mg/dL & 17,72 & 16,13 & 14,56 & 16,76 & 0,2045 & 13,941 \\
\hline Glicose, $\mathrm{mg} / \mathrm{dL}$ & 74,58 & 74,52 & 76,96 & 77,48 & 0,8896 & 10,044 \\
\hline
\end{tabular}

$\mathrm{P}=$ probabilidade $\mathrm{CV}=$ coeficiente de variação.

Suínos em crescimento, quando bem alimentados, apresentam valores de referência para concentrações de ureia sérica entre 10,0 e 30,0mg/dL (Kaneko et al., 2008). Pôde-se observar que as concentrações de ureia entre os tratamentos se mantiveram dentro dos valores recomendados, indicando aproveitamento proteico até o nível testado de $24 \%$. Esse resultado pode ter refletido nas respostas encontradas para as características de carcaça, que também não foram alteradas em função dos níveis de TA.

A concentração de ácido úrico sérico dos suínos apresentou uma redução linear $(\mathrm{P}=0,0023)$, em aproximadamente $31 \%$ em função dos níveis de inclusão da torta de algodão com adição de enzimas.

O ácido úrico é um composto orgânico produzido endogenamente pelos animais como um produto da degradação de purinas. Ele é formado pelo fígado e excretado pelos rins e intestino (So e Thorens, 2010). Na maioria dos mamíferos, entre eles os suínos, ocorre atividade de urato oxidase, por meio da enzima uricase, que auxilia na degradação do ácido úrico (Szczurek et al., 2017). Devido à presença dessa enzima, as concentrações de ácido úrico em suínos são abaixo de $2 \mathrm{mg} / \mathrm{dL}$ e dependerão do equilíbrio entre síntese e degradação de ácido úrico no organismo. Dessa forma, fatores como componentes da dieta podem influenciar diretamente a concentração plasmática ou sérica de ácido úrico.

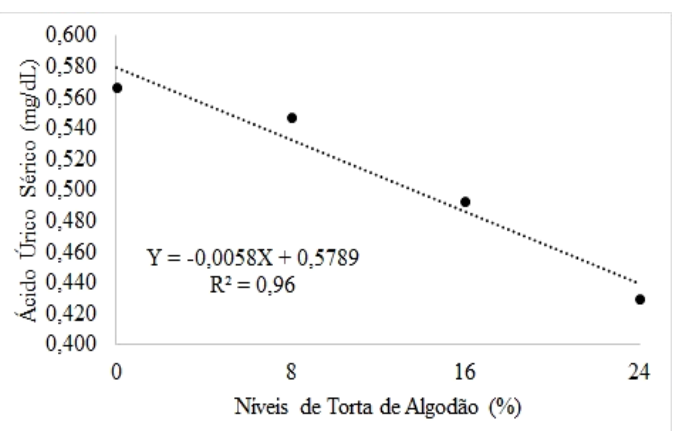

Figura 1. Concentração de ácido úrico sérico de suínos alimentados com rações contendo níveis crescentes de inclusão da torta de algodão.

O farelo de soja é uma excelente fonte de proteína. Segundo Kaneko et al. (2014), a soja possui maiores quantidades de purinas que outras leguminosas. Isso ocasionou a redução do ácido úrico sérico de acordo com a inclusão de TA, indicando que houve diminuição no nitrogênio livre, possivelmente devido à melhor absorção de proteína e à eficiência na utilização dos aminoácidos pelos animais, além da redução na excreção de nitrogênio. Contudo, tal fato não influenciou os parâmetros de desempenho entre os tratamentos, uma vez que o aumento da quantidade de substrato para ação das enzimas de acordo com os níveis crescentes de inclusão da TA forneceu a quantidade de proteína adequada 
para equiparar os resultados do tratamento com $24 \%$ e $0 \%$ de inclusão.

Os parâmetros de características de carcaça não foram influenciados $(\mathrm{P}>0,05)$ pelos níveis de torta de algodão das dietas (Tab. 4). O aumento do teor de fibra nas rações não interferiu também no produto final, como mostram os dados de rendimento de carcaça. Resultado semelhante foi encontrado por Paiano et al. (2014), que trabalharam com FA para suínos em crescimento e terminação até o nível de $15 \%$ de inclusão sem enzima.
No presente trabalho, não só a ET manteve-se próxima entre os tratamentos como também a AOL, provavelmente reflexo do desempenho obtido pelo uso de rações com complexo enzimático. A adição do complexo enzimático pode ter proporcionado melhora na digestibilidade da fibra nas rações, mantendo o desempenho semelhante entre os tratamentos, o que resultou em carcaças sem alteração na quantidade de carne magra, apesar de outros trabalhos testando níveis maiores de fibra nas dietas terem observado diminuição da espessura de toucinho (Meffeja et al., 2007; Poveda Parra et al., 2008).

Tabela 4. Características de carcaça de suínos alimentados com rações contendo níveis crescentes de inclusão da torta de algodão na fase de crescimento

\begin{tabular}{|c|c|c|c|c|c|c|}
\hline \multirow{2}{*}{ Variáveis } & \multicolumn{4}{|c|}{ Níveis de inclusão (\%) } & \multirow[b]{2}{*}{$\mathrm{P}$} & \multirow[b]{2}{*}{$\mathrm{CV} \%$} \\
\hline & 0,0 & 8,0 & 16,0 & 24,0 & & \\
\hline Rendimento de carcaça (\%) & 76,86 & 75,82 & 75,47 & 77,45 & 0,537 & 1,55 \\
\hline Rendimento de pernil (\%) & 28,03 & 28,57 & 28,24 & 29,22 & 0,222 & 3,29 \\
\hline Comprimento de carcaça $(\mathrm{cm})$ & 87,83 & 92,90 & 91,30 & 90,80 & 0,342 & 2,30 \\
\hline Espessura de toucinho (mm) & 24,22 & 21,77 & 22,72 & 21,22 & 0,305 & 11,30 \\
\hline Área de olho de lombo $\left(\mathrm{cm}^{2}\right)$ & 29,55 & 32,07 & 32,71 & 30,52 & 0,341 & 9,07 \\
\hline Relação carne/gordura & 1,96 & 1,84 & 1,67 & 2,10 & 0,739 & 32,63 \\
\hline
\end{tabular}

$\mathrm{P}=$ probabilidade; $\mathrm{CV}=$ coeficiente de variação.

Quanto à viabilidade econômica (Tab. 5), as rações com TA apresentaram redução nos custos por quilograma $(\mathrm{kg})$ de ração produzida, o que possivelmente se deve à menor quantidade de farelo de soja nessas rações. O tratamento com $24 \%$ de inclusão foi o que apresentou melhor IEE, demonstrando que esse tratamento teve o menor custo/kg de suíno produzido. A avaliação econômica realizada por Mello et al. (2012) apresentou aumento no custo de ração por quilograma de peso vivo com a inclusão dos níveis do farelo de algodão até $20 \%$ sem enzima. A redução de $1,5 \%$ nos valores de exigência em EM, PB e P com a utilização de $300 \mathrm{~g} / \mathrm{t}$ do complexo enzimático possivelmente explica essa melhoria nos resultados.

Tabela 5. Avaliação econômica da inclusão da torta de algodão nas rações de suínos em crescimento

\begin{tabular}{|c|c|c|c|c|c|c|}
\hline \multirow{2}{*}{ Variáveis } & \multicolumn{4}{|c|}{ Níveis de inclusão (\%) } & \multirow[b]{2}{*}{$\mathrm{P}$} & \multirow[b]{2}{*}{$\mathrm{CV} \%$} \\
\hline & 0,0 & 8,0 & 16,0 & 24,0 & & \\
\hline Custo/ kg de ração ( $\mathrm{R} \$ / \mathrm{kg}$ de ração) & 1,12 & 1,10 & 1,10 & 1,10 & - & - \\
\hline Custo/kg de PV (R $\$ / k g$ de PV) & $3,29^{\mathrm{a}}$ & $3,11^{\mathrm{a}}$ & $3,12^{\mathrm{a}}$ & $2,99^{\mathrm{b}}$ & 0,0136 & 5,94 \\
\hline Índice de eficiência econômica & 90,88 & 96,14 & 95,83 & 100 & - & - \\
\hline
\end{tabular}

$\mathrm{P}=$ probabilidade; $\mathrm{CV}=$ coeficiente de variação.

Letras diferentes na mesma linha diferem segundo teste de Dunnett a 95\% de confiança.

A torta de algodão suplementada com complexo enzimático até o nível máximo de $24 \%$ de inclusão testado neste experimento apresentou resultados semelhantes à ração referência, indicando melhoria na digestibilidade da fibra, o que sugere que o uso da TA com enzimas na dieta de suíno pode ser empregado sem prejuízo na produção, uma vez que a utilização de alimentos alternativos não precisa necessariamente ser melhor que o alimento padrão, basta que proporcione um desempenho equivalente e melhores resultados econômicos.

\section{CONCLUSÃO}

A torta de algodão pode ser utilizada em até $24 \%$ de inclusão com adição de complexo enzimático nas rações de suínos na fase de crescimento II, sem alterar parâmetros de desempenho e 
característica da carcaça, além de apresentar redução do custo/kg de suíno produzido.

\section{AGRADECIMENTOS}

À empresa Bioenzima, pela doação das enzimas, e ao Instituto Nacional de Ciência e Tecnologia INCT/CA, pelo financiamento parcial do experimento.

\section{REFERÊNCIAS}

ADENIJI, A.A.; AZEEZ, A.S. Effects of Feeding Growing Pigs Cotton Seed Cake with or without Fish Meal Supplementation. J. Appl. Sci. Res., v.4, p.12531256. 2008.

BARBOSA, H.P. et al. Triguilho para suínos nas fases de crescimento, crescimento e terminação. Rev. Bras. Zootec., v.21, p.827-837, 1992.

FANG, Z.F. et al. Responses of non-starch polysaccharide-degrading enzymes on digestibility and performance of growing pigs fed a diet based on corn, soya bean meal and Chinese double-low rapeseed meal. J. Anim. Physiol. Anim. Nutr., v.91. p.361-368. 2007.

GOMES, J.D.F. et al. Efeitos do incremento de fibra dietética sobre a digestibilidade, desempenho e características de carcaça: I. suínos em crescimento e terminação. Ciênc. Agrár., v.28, p.483-492. 2007.

GRIESHOP, C.M. et al. Nonstarch Polysaccharides and Oligosaccharides. In: LEWIS, A.J.; SOUTHERN, L.L. Swine nutrition. 2.ed. Boca Raton: CRC Press, 2001. cap.7, p.117-140.

HAUSCHILD, L. et al. Utilização do triticale e de enzimas em dietas para suínos: digestibilidade e metabolismo. Arq. Bras. Med. Vet. Zootec., v.60, p.470-476, 2008.

KANEKO, J.J. et al. Clinical biochemistry of domestic animals. 6.ed. New York: Academic Press, 2008. 928p.

KANEKO, K. et al. Total purine and purine base content of common foodstuffs for facilitating nutritional therapy for gout and hyperuricemia. Biol. Pharm. Bull., v.37, p.709-721, 2014.

LORENA-REZENDE, I.M.B. et al. Digestibility of the cottonseed meal with or without addition of protease and phytase enzymes in swine diet. Acta Sci. Anim. Sci., v.34, p.259-265, 2012.

MEFFEJA, F. et al. Influence de la substitution du tourteau de coton par le tourteau de palmiste dans l'alimentation des porcs en croissance finition. Livest. Res. Rural Devel., v.19, 2007.
MELLO, G. et al. Farelo de algodão em rações para suínos nas fases de crescimento e terminação. Arch. Zootec., v.61. p55-62. 2012.

MÉTODOS brasileiros de classificação de carcaças. Estrela: ABCS, 1973. p.14.

MOREIRA, I. et al. Utilização do farelo de algodão, com ou sem adição de ferro, na alimentação de leitões na fase inicial (15-30kg). Rev. Bras. Zootec., v.35, p.1077-1084. 2006.

PAIANO, D. et al. Farelo de algodão na alimentação de suínos (30-90 kg). Rev. Bras. Saúde Prod. Anim., v.15, p.790-800. 2014.

POVEDA PARRA, A.R. et al. Utilização da casca de café na alimentação de suínos nas fases de crescimento e terminação. Rev. Bras. Zootec., v.37, p.433-442. 2008.

RELATÓRIO anual. São Paulo: ABPA, 2016. Disponível em: <http://abpabr.com.br/storage/ files/versao_final_para_envio_digital_1925a_final_ab pa_relatorio_anual_2016_portugues_web1.pdf >.

Acesso em: 25 mar. 2017.

ROSTAGNO, H.S. et al. Tabelas brasileiras para aves e suínos - composição de alimentos e exigências nutricionais. 3.ed. Viçosa, MG: UFV, 2011. p.252.

RUIZ, U.S. et al. Complexo enzimático para suínos: digestão, metabolismo, desempenho e impacto ambiental. Rev. Bras. Zootec., v.37, p.458-468, 2008.

SILVA, C.A. et al. Utilização de um complexo enzimático para rações contendo farelo de gérmen de milho desengordurado para suínos e fase de crescimento. Semin. Ciênc. Agrár., v.34, p.4065-4082, 2013.

SO, A.; THORENS, B. Uric acid transport and disease. J. Clinic. Invest., v.120, p.1791-1799, 2010.

SYSTEM for windows, release 6.12. Cary: SAS, 2004. CD-ROM.

SZCZUREK, P. et al. Oral uricase eliminates blood uric acid in the hyperuricemic pig model. PLoS One, v.12, 2017. Disponível em: <https://www.ncbi.nlm.nih.gov/pmc/articles/PMC546 4639/pdf/pone.0179195.pdf >. Acesso em: 10 ago. 2018.

URRIOLA, P.E.; STEIN, H. H. Effects of distillers dried grains with solubles on amino acid, energy, and fiber digestibility and on hindgut fermentation of dietary fiber in a corn-soybean meal diet fed to growing pigs. J. Anim. Sci., v.88, p.1454-1462. 2010. 